\title{
Modulation of $a_{v} \beta_{6}$ integrin in osteoarthritis-related synovitis and the interaction with $\operatorname{VTN}_{(381-397 \text { a.a.) }}$ competing for TGF- $\beta 1$ activation
}

Federica Ciregia', Céline Deroyer ${ }^{1}$, Gaël Cobraiville ${ }^{1}$ Zelda Plener ${ }^{1}$, Olivier Malaise ${ }^{1}$, Philippe Gillet ${ }^{2}$, Marianne Fillet ${ }^{3}$, Michel G. Malaise ${ }^{1}$ and Dominique de Seny ${ }^{1}$

\begin{abstract}
Osteoarthritis is characterized by structural alteration of joints. Fibrosis of the synovial tissue is often detected and considered one of the main causes of joint stiffness and pain. In our earlier proteomic study, increased levels of vitronectin (VTN) fragment (amino acids 381-397) were observed in the serum of osteoarthritis patients. In this work, the affinity of this fragment for integrins and its putative role in TGF- $\beta 1$ activation were investigated. A competition study determined the interaction of $\mathrm{VTN}_{(381-397 \text { a.a.) }}$ with $a_{\mathrm{v}} \beta_{6}$ integrin. Subsequently, the presence of $a_{v} \beta_{6}$ integrin was substantiated on primary human fibroblast-like synoviocytes (FLSs) by western blot and flow cytometry. By immunohistochemistry, $\beta_{6}$ was detected in synovial membranes, and its expression showed a correlation with tissue fibrosis. Moreover, $\beta_{6}$ expression was increased under TGF- $\beta 1$ stimulation; hence, a TGF- $\beta$ bioassay was applied. We

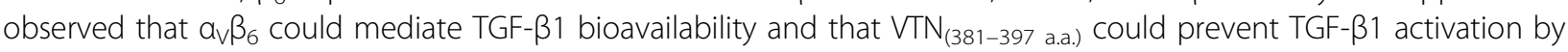
interacting with $a_{\sqrt{ }} \beta_{6}$ in human FLSs and increased a-SMA. Finally, we analyzed serum samples from healthy controls and patients with osteoarthritis and other rheumatic diseases by nano-LC/Chip MS-MS, confirming the increased expression of $\operatorname{VTN}_{(381-397 \text { a.a.) }}$ in osteoarthritis as well as in lupus erythematosus and systemic sclerosis. These findings corroborate our previous observations concerning the overexpression of $\operatorname{VTN}_{(381-397 \text { а.а) }}$ in osteoarthritis but also in other rheumatic diseases. This fragment interacts with $a_{v} \beta_{6}$ integrin, a receptor whose expression is increased in FLSs from the osteoarthritic synovial membrane and that can mediate the activation of the TGF- $\beta 1$ precursor in human FLSs.
\end{abstract}

\section{Introduction}

Osteoarthritis $(\mathrm{OA})$ is one of the most prevalent chronic joint diseases. This condition is more common in women and those over the age of 65, with a peak incidence around the age of 75 years $^{1,2}$. Its prevalence is increasing worldwide due to the increasing rates of obesity and aging ${ }^{1}$. OA is characterized by structural alterations in the whole joint that typically exhibit cartilage degradation, subchondral

\footnotetext{
Correspondence: Federica Ciregia (federica.ciregia@uliege.be)

${ }^{1}$ Laboratory of Rheumatology, GIGA-I3, University of Liège, CHU de Liège,

Liège, Belgium

${ }^{2}$ Department of Orthopedic Surgery, University Hospital Sart-Tilman, Liege,

Belgium

Full list of author information is available at the end of the article

These authors contributed equally: Michel G. Malaise, Dominique de Seny
}

bone sclerosis, and osteophyte formation. However, osteoarthritic synovium can also acquire an inflammatory phenotype, as mostly encountered in rheumatoid arthritis (RA), characterized by hyperplasia, leukocyte infiltration, neoangiogenesis, and fibrosis ${ }^{3,4}$. Cartilage and synovial fibrosis resulting from chronic inflammation and tissue injury have only been recently highlighted in $\mathrm{OA}^{3,5,6}$. Indeed, OA synovial tissue becomes rigid and thick, but the mechanisms that underlie fibrosis are still elusive. Synovial fibroblasts promote cell transformation into myofibroblasts expressing $\alpha$-smooth muscle actin $2(\alpha$ SMA) as well as excessive secretion of extracellular matrix (ECM) components ${ }^{7}$. TGF- $\beta$ is one of the main players in fibrosis and is crucial for the fibrotic cascade activated in

\section{(c) The Author(s) 2021}

\footnotetext{
(c) (i) Open Access This article is licensed under a Creative Commons Attribution 4.0 International License, which permits use, sharing, adaptation, distribution and reproduction cc in any medium or format, as long as you give appropriate credit to the original author(s) and the source, provide a link to the Creative Commons license, and indicate if changes were made. The images or other third party material in this article are included in the article's Creative Commons license, unless indicated otherwise in a credit line to the material. If material is not included in the article's Creative Commons license and your intended use is not permitted by statutory regulation or exceeds the permitted use, you will need to obtain permission directly from the copyright holder. To view a copy of this license, visit http://creativecommons.org/licenses/by/4.0/.
} 
$\mathrm{OA}^{6}$. TGF- $\beta$ is secreted in a latent form (pro-TGF- $\beta$ ), which is biologically inactive and associated with a noncovalent complex with the ECM. During biosynthesis, pro-TGF- $\beta$ dimerizes through disulfide, which links to latent TGF- $\beta$-binding proteins (LTBPs) or glycoprotein-A repetitions predominant protein in large latent complexes. In response to injury, latent TGF- $\beta$ complexes are modified into active TGF- $\beta$ according to a tissue- and injury type-specific activation mechanism ${ }^{8}$. Integrin $\alpha_{\mathrm{V}} \beta_{6}$ is known to activate the latent form of TGF- $\beta 1$. Integrins are receptors that connect the cytoskeleton to the ECM. They are heterodimers made up of noncovalently associated $\alpha$ and $\beta$ subunits. In mammals, there are 18 different $\alpha$ subunits and $8 \beta$ subunits that can form 24 distinct heterodimers ${ }^{9,10}$. Integrins interact with different ligands (e.g., fibronectin and vitronectin (VTN)) that are mainly ECM molecules. They play an important role in cell adhesion but also in cell movement and migration. Integrins differ in tissue distribution and ligand identification. Recently, it has been reported that $\alpha_{\mathrm{V}} \beta_{5}, \alpha_{\mathrm{V}} \beta_{3}$, and $\alpha_{\mathrm{V}} \beta_{6}$ interact with $\mathrm{PRGD}_{2}$, and their expression levels are increased in osteoarthritic cartilage and osteophytes ${ }^{11}$. Integrin $\alpha_{V} \beta_{6}$ interacts with molecules that contain the Arg-Gly-Asp (RGD) motif. Its formation is determined by $\beta_{6}$ expression, since it can form a dimer only with $\alpha_{V}$, while $\alpha_{V}$ can interact with other $\beta$ subunits (i.e., $\beta_{1}, \beta_{3}, \beta_{5}$, and $\left.\beta_{8}\right)^{12}$. Integrin $\alpha_{v} \beta_{6}$ is known to be involved in the activation of TGF- $\beta 1$ by interacting with the latencyassociated peptide (LAP) of TGF- $\beta 1$ through its RGD motif ${ }^{13}$. Integrin $\alpha_{\mathrm{V}} \beta_{6}$ plays a role in fibrosis, as suggested by Munger and colleagues, who observed that mice lacking integrin $\alpha_{\mathrm{V}} \beta_{6}$ were protected from pulmonary fibrosis ${ }^{13}$. Indeed, in normal adult skin, kidney, lung, and liver, epithelial cells have low or absent basal expression of $\alpha_{v} \beta_{6}$ integrin, while it is upregulated in inflammation, cancer, wounds, and fibrosis ${ }^{9,14}$. In a previous study, we found increased levels of a V65 vitronectin fragment, $\operatorname{VTN}_{(381-397 \text { a.a.) }}$, in the synovial fluid and serum of OA patients with respect to controls (healthy and RA subjects ${ }^{15}$. VTN is an ECM protein that participates in cell migration, adhesion, and spreading ${ }^{16-18}$. This protein interacts with $\alpha_{\mathrm{V}}$-containing integrins and specifically with $\alpha_{v} \beta_{3}$ integrin through its RGD motif ${ }^{19}$. VTN also plays a positive role in fibrosis ${ }^{18,20,21}$. Interestingly, the fragment $\mathrm{VTN}_{(381-397 \text { a.a.) }}$ is the result of VTN cleavage by plasmin, which affects the interaction of plasminogen activator inhibitor-1 (PAI-1) with VTN. Hence, PAI-1 is no longer trapped in the ECM, can inhibit plasminogen activation and may potentially mediate fibrosis ${ }^{22,23}$.

The aim of this work is therefore to investigate (i) whether $\operatorname{VTN}_{(381-397}$ a.a.) can interact with integrin complexes, (ii) if $\alpha_{\mathrm{V}} \beta_{6}$ is expressed in synovitis in OA, (iii) if $\alpha_{v} \beta_{6}$ can activate latent TGF- $\beta 1$, and (iv) how $\operatorname{VTN}_{(381-397 \text { a.a.) }}$ can compete with TGF- $\beta 1$. The presence of $\operatorname{VTN}_{(381-397}$ a.a.) will also be investigated in other rheumatic diseases.

\section{Materials and methods \\ Competition study}

A competition study was performed to investigate the interaction of $\operatorname{VTN}_{(381-397 \text { a.a.) }}$ with five different integrins. Radiolabeled echistatin, a disintegrin known to bind integrin receptors, was used as a tracer for the binding assays. Lyophilized echistatin was provided by Bachem (Bubendorf, Switzerland) and radiolabeled by conjugation with a radioiodinated benzoate $\left({ }^{125} \mathrm{ISIB}\right)$ to the epsilon amino group of lysine side chains. For the five integrins, $\alpha_{5} \beta_{1}, \alpha_{V} \beta_{1}, \alpha_{V} \beta_{3}, \alpha_{V} \beta_{5}$, and $\alpha_{V} \beta_{6}$ (R\&D System; Minneapolis, MN, USA), a solution at $1.8 \mu \mathrm{g} / \mathrm{mL}$ was prepared with integrin-binding buffer (IBB; $20 \mathrm{mM}$ Tris $\mathrm{pH} 7.4$, $150 \mathrm{mM} \mathrm{NaCl}, 2 \mathrm{mM} \mathrm{CaCl}, 1 \mathrm{mM} \mathrm{MgCl} 2,1 \mathrm{mM} \mathrm{MnCl} 2$ ). Nunc Maxisorp Module plates were coated overnight at $4{ }^{\circ} \mathrm{C}$ with integrin complex at $1.8 \mu \mathrm{g} / \mathrm{mL}$. After the wells were washed with sample buffer (IBB, 0.5\% BSA), blocking solution (IBB, $2 \% \mathrm{BSA}$ ) was added, and the microplate was incubated for $2 \mathrm{~h}$ at room temperature. The wells were then washed three times with IBB $/ 0.5 \%$ BSA. Then, ${ }^{125}$ ISIB-echistatin was diluted in sample buffer to fixed concentrations of 4, 4, 8, 8, and $20 \mathrm{nM}$ for $\alpha_{5} \beta_{1}, \alpha_{\mathrm{V}} \beta_{1}$, $\alpha_{\mathrm{V}} \beta_{3}, \alpha_{\mathrm{V}} \beta_{5}$, and $\alpha_{\mathrm{V}} \beta_{6}$ competition studies, respectively. The ${ }^{125}$ ISIB-echistatin was mixed with sample buffer at a ratio of $1: 1$ (total binding = control well) or with increasing concentrations of ligands (Supplementary information SI1) [complete VTN, $\operatorname{VTN}_{(381-397}$ a.a.), $\operatorname{VTN}_{(365-381}$ a.a.) $]$ at a ratio $1: 1$ and added to wells in duplicate. We used 1,4,7-triazacyclononane-1,4,7-triacetic acid (NOTA) as a negative control. Then, $100 \mu \mathrm{L}$ of prepared solutions $\left({ }^{125}\right.$ ISIB-echistatin and ligands) was added to the plate and incubated for $2 \mathrm{~h}$ at room temperature with agitation. After rinsing, bound radioactivity was quantified using a gamma counter. The percentage of relative binding of radiolabeled echistatin was calculated as follows: radioactivity in the test well*100/radioactivity in the reference well. The reference well represents the total binding without ligand. For comparison of the potency of ligands in inhibiting bound ${ }^{125}$ ISIB-echistatin for different integrin complexes, the half-maximal inhibitory concentration $\left(\mathrm{IC}_{50}\right)$ was calculated. The $\mathrm{IC}_{50}$ value was determined by constructing a dose-response curve and examining the effect of different concentrations of ligands on ${ }^{125}$ ISIB-echistatin binding. The experimental data were subjected to nonlinear regression using a fiveparameter logistical model with GraphPrism 7 software.

\section{Primary cell culture and treatment}

Synovial membranes were obtained from 22 OA patients (14 females, 8 males; mean age $69.8 \pm 9.6$ years, BMI $30.9 \pm$ 6.8) during knee replacement, and primary synovial 
fibroblasts were isolated as explained previously ${ }^{24}$. The research ethics committee of CHU de Liege (Belgium) approved the study, and the patient gave informed consent to allow research procedures on samples. Human fibroblast-like synoviocytes (FLSs) were then cultured in DMEM supplemented with $10 \%$ FBS, $1 \%$ Pen/Strep, and 1\% L-glutamine (all from Lonza; Basel, Switzerland) at $37^{\circ} \mathrm{C}$ in an atmosphere of $5 \% \mathrm{CO}_{2}$. In a plate, $5 \times 10^{4} \mathrm{FLSs}$ were stimulated with different compounds to analyze the modulation of $\alpha_{\mathrm{v}} \beta_{6}$ : (i) TGF- $\beta 1$, TNF- $\alpha$, IL- $1 \beta$, or IL- 6 were used for 3 or 7 days at a concentration of $10 \mathrm{ng} / \mathrm{mL}$; (ii) among the danger-associated molecular patterns, high-mobility group box 1 (HMGB1) was tested at 10, 50, and $100 \mathrm{ng} / \mathrm{mL}$ for 3 days, while S100A9 and S100A12 were tested at 100 and $200 \mathrm{ng} / \mathrm{mL}$ for 3 days or $24 \mathrm{~h}$; (iii) advanced glycation end product (AGE-BSA) was tested at 50,100 , and $200 \mu \mathrm{g} / \mathrm{mL}$ for 3 days or $24 \mathrm{~h}$; (iv) prednisolone and dexamethasone were used at $1 \mu \mathrm{M}$ for 3 or 7 days; and (v) menadione or $\mathrm{H}_{2} \mathrm{O}_{2}$ was used to induce oxidative stress at $25-50-100 \mu \mathrm{M} \quad(3 \mathrm{~h})$ and $100-200-400 \mu \mathrm{M}(2 \mathrm{~h})$, respectively, without FBS in the medium.

Finally, for analysis of the expression of $\alpha$-SMA, FLSs $(n=5)$ were stimulated with $\operatorname{VTN}_{(381-397 \text { a.a.) }}(10,25,50$, $100 \mathrm{ng} / \mathrm{mL})$ with or without TGF- $\beta 1(10 \mathrm{ng} / \mathrm{mL})$ for 7 days.

\section{Western blot}

The expression of $\alpha_{V}$ and $\beta_{6}$ subunits and $\alpha$-SMA in FLSs was evaluated by western blot analysis. Cells were scraped from plates and lysed with lysis buffer $(25 \mathrm{mM}$ HEPES, $150 \mathrm{mM} \mathrm{NaCl}, 0.5 \%$ Triton, $10 \%$ glycerol, $1 \mathrm{mM}$ dithiothreitol) containing phosphatase inhibitors $(25 \mathrm{mM}$ $\beta$-glycerophosphate, $1 \mathrm{mM} \mathrm{Na}_{3} \mathrm{VO}_{4}$, and $1 \mathrm{mM} \mathrm{NaF}$ ) and complete protease inhibitor mixture (Roche Applied Science; Penzberg, Germany). Total proteins were separated by $10 \%$ SDS-PAGE gels ( $12 \%$ for $\alpha$-SMA) and transferred onto PVDF membranes. The membranes were then incubated with anti- $\alpha_{V}$ polyclonal antibody (1:250 dilution) (Cell Signaling Technology; Boston, MA, USA), anti$\beta_{6}$ polyclonal antibody (1:1000 dilution) (Abcam; Cambridge, UK) or anti- $\alpha$-SMA monoclonal antibody (Agilent; Santa Clara, CA, USA; 1:1000 dilution). HRP-conjugated anti-rabbit antibody (1:1000 dilution) (Cell Signaling Technology) was used as the secondary antibody. Immunoblots were developed using the ECL chemiluminescent detection system. Rabbit anti-glyceraldehyde 3-phosphate dehydrogenase (GAPDH) (Merck) or rabbit anti-heat shock protein 90 (Hsp90; Santa Cruz) was used as loading controls at a dilution of $1: 10,000$ or 1:200, respectively. Values of optical intensity were normalized to GAPDH or Hsp90 levels. Data were analyzed by paired Wilcoxon test; a $p$-value $<0.05$ was considered statistically significant. Statistical analysis was performed with GraphPad Prism 6 software (San Diego, CA, USA).

\section{Flow cytometry}

Flow cytometry fluorescence-activated cell sorting (FACS) was applied to detect the presence of $\alpha_{\mathrm{V}} \beta_{6}$ integrin in FLSs. FLSs $(n=4)$ were detached by scraping and harvested on ice-cold PBS containing $1 \mathrm{mM} \mathrm{MgCl} 2$ and $0.1 \%$ BSA; $4 \times 10^{5}$ cells were used for each condition. The cell scraper was used to prevent ablation induced by trypsin, and the experiment was performed on ice to prevent integrin internalization ${ }^{25}$. U87 glioblastoma cells that naturally expressed $\alpha_{\mathrm{v}} \beta_{6}$ integrin were used as a positive control ${ }^{26}$. Primary antibody recognizing $\alpha_{V} \beta_{6}$ integrin (Merck; Darmstadt, Germany) was used at a concentration of $100 \mu \mathrm{g} / \mathrm{mL}$ in $\mathrm{PBS} / \mathrm{MgCl}_{2} / \mathrm{BSA}$. After incubation for $40 \mathrm{~min}$ on ice and two washes with PBS/ $\mathrm{MgCl}_{2} / \mathrm{BSA}$, the cells were incubated for $20 \mathrm{~min}$ on ice in the dark with Alexa Fluor 647-conjugated goat antimouse antibody (Thermo Fisher Scientific). After two washes, the cells were resuspended in $500 \mu \mathrm{L}$ of PBS/ $\mathrm{MgCl}_{2} / \mathrm{BSA}$ and filtered with a $100 \mu \mathrm{m}$ strainer (Sysmex; Norderstedt, Germany) in FACS tubes; $1 \mu \mathrm{L}$ of DAPI dye (Thermo Fisher Scientific) was added to identify dead cells. Flow cytometric measurements were performed with a FACSCanto ${ }^{\mathrm{TM}}$ II (BD Biosciences; San Jose, CA, USA), and $10^{4}$ cells were analyzed in each assay. Flow cytometry standard files were then analyzed by Flowjo ${ }^{\mathrm{TM}}$ software (BD Biosciences).

\section{Immunohistochemistry (IHC) of formalin-fixed paraffin- embedded tissues}

Synovial biopsies $(n=23)$ were collected from synovial membranes provided from OA $(n=9)$, chronic pyrophosphate arthropathy (CPPA) $(n=7)$, and RA patients $(n=7)$ by needle arthroscopy from the affected knees (Table 1). These biopsies were fixed in $4 \%$ paraformaldehyde for $24 \mathrm{~h}$ at $4{ }^{\circ} \mathrm{C}$, embedded in paraffin and characterized according to the histological inflammatory score (HIS) based on Tak's score ${ }^{27}$. Briefly, HIS was obtained by hematoxylin-eosin staining measuring hyperplasia (0-4), infiltration of lymphocytes (0-4), plasma cells $(0-4)$ and neutrophils $(0-3)$ and by IHC for the infiltration of macrophages (CD68 staining, 0-3), leading to a total HIS of 18 . The greater the score was, the greater the inflammatory status was.

For IHC, slides were first incubated overnight at $65^{\circ} \mathrm{C}$. The day after, sections were dewaxed in xylene and subsequently passed through $100 \%$ ethanol and $70 \%$ ethanol. The unmasking was performed at $80^{\circ} \mathrm{C}$ for $20 \mathrm{~min}$. Endogenous peroxidase activity was then inactivated with $3 \% \mathrm{H}_{2} \mathrm{O}_{2}$ for 20 min followed by blocking. Specific antibodies for $\beta_{6}$ (Abcam) or $\alpha$-SMA (Agilent) were used $\mathrm{O} / \mathrm{N}$ diluted $1 / 500$ or $1 / 50$, respectively. Rinsed slides were incubated with HRP-labeled anti-rabbit antibody (Agilent) in a humidified chamber for $30 \mathrm{~min}$ at RT. Peroxidase was revealed with a Liquid $\mathrm{DAB}+$ Substrate 
Table 1 Clinical features of patients from whom synovial biopsies were collected after needle arthroscopy of the knee.

\begin{tabular}{llll}
\hline & OA & CPPA & RA \\
\hline No. & 9 & 7 & 7 \\
Female (no.) & 8 & 5 & 5 \\
Age (median \pm SD) & $55 \pm 14$ & $65 \pm 9$ & $61 \pm 17$ \\
BMI (median \pm SD) & $33 \pm 7$ & $24 \pm 4$ & $24 \pm 5$ \\
ESR+ & $1 / 9$ & $0 / 7$ & $3 / 7$ \\
CRP+ & $2 / 9$ & $3 / 7$ & $6 / 7$ \\
RF+ & $0 / 9$ & $0 / 7$ & $2 / 7$ \\
Anti-CCP+ & $0 / 9$ & $0 / 7$ & $2 / 7$ \\
K\&L score-median (interval) & $3(0-4)$ & $2(0-4)$ & n.d. \\
Histological inflammatory score median & $4(3-8)$ & $5(5-13)$ & $14(12-17)$ \\
(interval) & & & \\
\hline
\end{tabular}

$O A$ Osteoarthritis, CPPA chronic pyrophosphate arthropathy, RA rheumatoid arthritis patients, $B M I$ body mass index, ESR erythrocyte sedimentation rate, $C R P$ C-reactive protein, $R F$ rheumatoid factor, anti-CCP anti-cyclic citrullinated peptide, K\&L score Kellgren and Lauwrence score peptide.

Chromogen System (Agilent) for $10 \mathrm{~min}$ in a humidified chamber. Rinsed sections were counterstained for $30 \mathrm{~s}$ with Carazzy's hematoxylin. Staining was detected with a Nanozoomer Digital Pathology 2.0 HT scanner (Hamamatsu Photonics, Hamamatsu, Japan). Images derived from IHC were analyzed with the bioimage analysis software QuPath ${ }^{28}$.

\section{TGF- $\beta$ bioassay}

Transformed mink lung epithelial cells (TMLCs), a generous gift from Prof. DB Rifkin (Department of Cell Biology, NYU School of Medicine, New York, NY), were used to test TGF- $\beta 1$ functionality ${ }^{29}$. TMLCs were cultured in DMEM supplemented with 10\% FBS, 1\% Pen/ Strep, and $1 \mathrm{mg} / \mathrm{mL}$ G418 Sulfate (Biowest; Riverside, MO, USA). For coculture, TMLCs were plated in 96-well plates at a density of $10^{4}$ cells per well, and fibroblasts were added at a density of $1.5 \times 10^{4}$ cells per well, with a final volume of $100 \mu \mathrm{L}$. Cells were allowed to attach at $37^{\circ} \mathrm{C}$ and $5 \% \mathrm{CO}_{2}$. After $6 \mathrm{~h}$, the medium was removed and replaced by the different treatments diluted in medium with $0.1 \%$ BSA without FBS (final volume of $100 \mu \mathrm{L}$ ).

For function-blocking experiments, cells were incubated with anti- $\alpha_{\mathrm{V}} \beta_{6}$ antibody (clone 10D5; Merck) or with the isotype control IgG2a kappa (clone eBM2a; Thermo Fisher Scientific) for $20 \mathrm{~min}$ at room temperature at a concentration of $50 \mu \mathrm{g} / \mathrm{mL}$ in medium containing $1 \mathrm{mM}$ $\mathrm{MgCl}_{2} / 0.1 \%$ BSA before adding other compounds. Human latent TGF- $\beta 1$ (hlatent TGF- $\beta 1$; Cell Signaling Technology) was added at a concentration of $200 \mathrm{ng} /$ $\mathrm{mL}^{30}$. For acidic activation, hlatent TGF- $\beta 1$ was incubated for 10 min with $1 \mathrm{~N} \mathrm{HCl}$ and neutralized by $1.2 \mathrm{~N} \mathrm{NaOH} /$ 0.5 M HEPES before it was added to cells. $\operatorname{VTN}_{(381-397 \text { a.a. }}$ (Thermo Fischer Scientific) and hepcidin were used at $50 \mathrm{ng} / \mathrm{mL}$. After $16 \mathrm{~h}$ of incubation at $37^{\circ} \mathrm{C}$ and $5 \% \mathrm{CO}_{2}$, the cells were washed with PBS and lysed by using $75 \mu \mathrm{L}$ of cell culture lysis reagent (Promega, Madison, WI, USA) for $30 \mathrm{~min}$ at room temperature on a plate shaker. Luciferase activity was assessed by plate-reading luminometers with an injector (Victor ${ }^{\mathrm{TM}} \mathrm{X}$; PerkinElmer Waltham, MA, USA) adding $100 \mu \mathrm{l}$ of luciferase assay reagent (Promega) per well. Each condition was performed in triplicate for six different donors.

The data are expressed as relative luciferase activity (RLA). RLA is the measured luciferase activity of the coculture divided by the activity of the related control alone under the same conditions. Data were analyzed with the paired Wilcoxon test for non-normal data; a $p$-value $<$ 0.05 was considered statistically significant. Statistical analysis was performed with GraphPad Prism 6 software.

\section{Serum collection}

Thirty-eight healthy subjects and 38 OA patients were enrolled in the study to quantify the expression of the V65 fragment of VTN ( ${ }_{381}$ SQRGHSRGRNQNSRRPS $_{397}$ ) or $\operatorname{VTN}_{(381-397 \text { a.a.) }}$. Blood samples were also collected from patients with different chronic inflammatory diseases: 46 with RA, 30 with ankylosing spondylitis (AS), 23 with systemic lupus erythematosus (SLE), and 20 with systemic sclerosis (SSc). OA patients were sorted into the early OA $(n=13)$ and late OA $(n=25)$ groups according to the K\&L score. Data of the participants are summarized in Table 2. Human blood samples were collected under standard conditions and allowed to coagulate in plain glass tubes. Serum was obtained after centrifugation at $3000 \mathrm{rpm}$ for $10 \mathrm{~min}$ at room temperature. Aliquots of supernatants were prepared and stored at $-80^{\circ} \mathrm{C}$ until use. The study was approved by the local institutional review boards of CHU Hospital of Liège.

\section{Nano-LC/Chip MS-MS}

The levels of the V65 fragment of VTN in serum samples were analyzed as previously described ${ }^{31}$. Briefly, serum samples and calibration solution were purified and concentrated on an Oasis $\mu$ Elution WCX 96-well plate (Waters Corporation, Dublin, Ireland) before chromatographic separation and mass spectrometry analysis. ProtID-chip Zorbax 300SB (5 $\mu \mathrm{m}$ C18 phase, Agilent Technologies; Santa Clara, CA, USA) was used for chromatographic separation in gradient mode. A nanochip ESI source was operating in positive mode, and protonated peptide detection was performed by ion trap mass spectrometry (Agilent Technologies, Ion Trap LC/MS G6340A). The MS and MS/MS experimental parameters were optimized to be as sensitive and selective as possible. 
Table 2 Clinical characteristics of patients enrolled in the study.

\begin{tabular}{|c|c|c|c|c|c|c|c|}
\hline & $\mathrm{HC}$ & early $O A$ & late $\mathrm{OA}$ & RA & AS & SLE & SSc \\
\hline$n$ & 38 & 13 & 25 & 46 & 30 & 23 & 20 \\
\hline$\%$ Female & 63 & 77 & 84 & 70 & 40 & 87 & 55 \\
\hline Age-median (range) & $48(24-72)$ & $64(51-77)$ & $68(61-86)$ & $55(17-77)$ & $50(23-71)$ & $42(17-68)$ & $57(37-83)$ \\
\hline BMI-Median (range) & $23(19-28)$ & - & - & $25(16-40)$ & - & $22(17-31)$ & $24(19-32)$ \\
\hline DAS (range) & - & - & - & $4.2(0.5-8)$ & - & - & - \\
\hline ESR\% & - & 9 & 11 & 57 & 40 & 24 & 15 \\
\hline $\mathrm{CRP}+\%$ & - & 18 & 21 & 47 & 45 & 15 & 45 \\
\hline$R F+\%$ & - & 0 & 0 & 63 & - & - & - \\
\hline Anti-CCP+\% & - & 0 & 0 & 85 & - & - & - \\
\hline HLA-B27+\% & - & - & - & - & 86 & - & - \\
\hline
\end{tabular}

$H C$ healthy control, $O A$ osteoarthritis, $R A$ rheumatoid arthritis, $A S$ ankylosing spondylitis, SLE systemic lupus erythematosus, SSC systemic sclerosis, $B M I$ body mass index, DAS disease activity score, ESR erythrocyte sedimentation rate, CRP C-reactive protein, $R F$ rheumatoid factor, anti-CCP anti-cyclic citrullinated peptide, $H L A-B 27$ human leukocyte antigen.

The intensities of the selected product ions were summed to extract ion chromatograms and subsequently integrated (QuantAnalysis software, Bruker Daltonik GmbH; Billerica, MA, USA). Area ratios (peptide vs. labeled peptide) were considered for quantitation. The linearity of the results for fragment quantitation was validated in the concentration range of $2.5-100 \mathrm{ng} / \mathrm{mL}$, and the limit of detection was $0.76 \mathrm{ng} / \mathrm{mL}$.

Differences in expression of $\operatorname{VTN}_{(381-397}$ a.a.) among the examined classes of patients were analyzed with the unpaired Kolmogorov-Smirnov tests for nonparametric data.

\section{Results}

Integrin binding specificity of $\mathrm{VTN}_{(381-397}$ a.a.)

To determine if $\operatorname{VTN}_{(381-397 \text { a.a. })}$ could interact with integrins, we investigated its ability to compete with radiolabeled echistatin for binding to five different integrin complexes: $\alpha_{5} \beta_{1}, \alpha_{V} \beta_{1}, \alpha_{V} \beta_{3}, \alpha_{V} \beta_{5}$ and $\alpha_{V} \beta_{6}$. We also tested the binding affinity of the whole VTN protein and another VTN fragment, $\operatorname{VTN}_{(365-381 \text { a.a) }}$, as previously described by Maile et al. ${ }^{32,33}$. First, the binding affinity of echistatin to the five integrins was measured by determining the equilibrium dissociation constant $\left(K_{\mathrm{D}}\right) . K_{\mathrm{D}}$ was evaluated by saturation assays involving addition of increasing concentrations of radiolabeled echistatin to a constant concentration of integrins (coated at $1.8 \mu \mathrm{g} / \mathrm{mL}$ ). The $K_{\mathrm{D}}$ values calculated for each integrin complex were 1.48, 0.99, 3.17, 3.46, and 17.05 for $\alpha_{5} \beta_{1}, \alpha_{V} \beta_{1}, \alpha_{V} \beta_{3}, \alpha_{V} \beta_{5}$, and $\alpha_{V} \beta_{6}$, respectively. Subsequently, competitive experiments were performed using increasing concentrations of ligand and a fixed amount of radiolabeled echistatin. The fixed concentration of radiolabeled echistatin was determined according to its $K_{\mathrm{D}}$ value. For each ligand concentration, the relative binding of ${ }^{125}$ ISIB-echistatin to coated integrins was then measured, and values were plotted versus the logarithm of ligand concentration. These competition curves together with the derived $\mathrm{IC}_{50}$ values are shown in Fig. 1 . The $\operatorname{VTN}_{(381-397}$ a.a.) peptide exhibited binding affinity only for integrin $\alpha_{\mathrm{V}} \beta_{6}\left(\mathrm{IC}_{50}=\right.$ $3.2 \mu \mathrm{M})$, as also observed with the other $\operatorname{VTN}_{(365-381}$ a.a.) fragment $\left(\mathrm{IC}_{50}=0.79 \mu \mathrm{M}\right)$. The whole VTN protein also exhibited a high affinity for $\alpha_{\mathrm{V}} \beta_{6}\left(\mathrm{IC}_{50}=0.25 \mu \mathrm{M}\right)$ but also for $\alpha_{\mathrm{V}} \beta_{3}\left(\mathrm{IC}_{50}=1.5 \mu \mathrm{M}\right)$ and $\alpha_{\mathrm{V}} \beta_{5}\left(\mathrm{IC}_{50}=0.13 \mu \mathrm{M}\right)$, as expected.

Therefore, considering that (i) the levels of cleaved $\operatorname{VTN}_{(381-397 \text { a.a. })}$ fragments were increased in the serum and synovial fluid of OA patients ${ }^{15}$ and (ii) this fragment interacts with integrin $\alpha_{V} \beta_{6}$, we investigated the expression of $\alpha_{V} \beta_{6}$ integrin in OA synovial tissue.

\section{Integrin $a_{V} \beta_{6}$ expression in FLSs and OA-related synovitis In vitro and in situ expression of $\alpha_{V}$ and $\beta_{6}$ subunits or the $a_{v} \beta_{6}$ complex on FLSs}

First, the expression of each subunit of the $\alpha_{V} \beta_{6}$ integrin was observed by western blot analysis using human FLSs provided from the synovial membrane of $\mathrm{OA}$ patients (Fig. 2a). Second, the expression of the $\alpha_{V} \beta_{6}$ integrin complex was determined by FACS analysis and illustrated by a flow cytometric histogram obtained with human FLSs previously incubated with $\alpha_{\mathrm{v}} \beta_{6}$ antibodies (Fig. 2b). As a negative control, FACS analysis was applied to FLSs incubated with only the secondary antibody (to exclude any nonspecific binding with the secondary antibody) and to FLSs with no antibody (to control the background derived from autofluorescence). Cells positive for DAPI were considered dying and were excluded from analysis by gating. The mean fluorescence intensity $(\mathrm{MFI} \pm \mathrm{SD})$ 


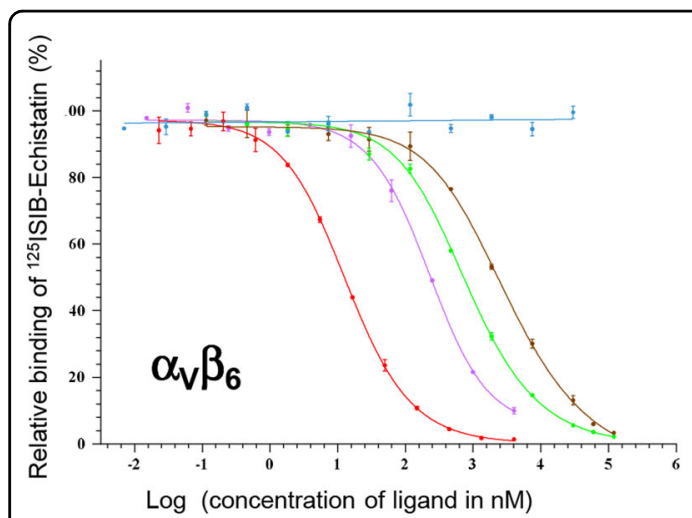

$\operatorname{VTN}\left(381-397\right.$ aa): $I C_{50}=3.2 \mu \mathrm{M}$ $\operatorname{VTN}(365-381 \mathrm{aa}): \mathrm{IC}_{50}=0.79 \mu \mathrm{M}$ VTN: $I C_{50}=0.25 \mu \mathrm{M}$

Echistatin: $\mathrm{IC}_{50}=0.014 \mu \mathrm{M}$

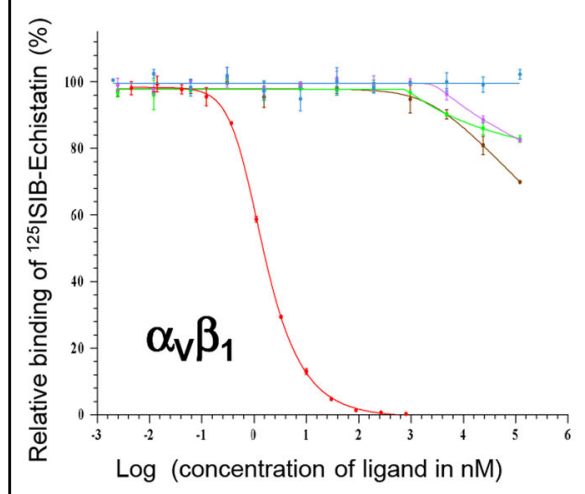

Echistatin: $\mathrm{IC}_{50}=0.0015 \mu \mathrm{M}$

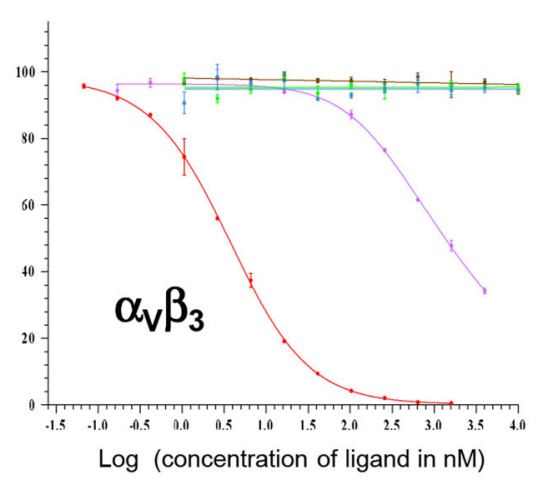

VTN: $I C_{50}=1.5 \mu \mathrm{M}$ Echistatin: $\mathrm{IC}_{50}=0.0037 \mu \mathrm{M}$

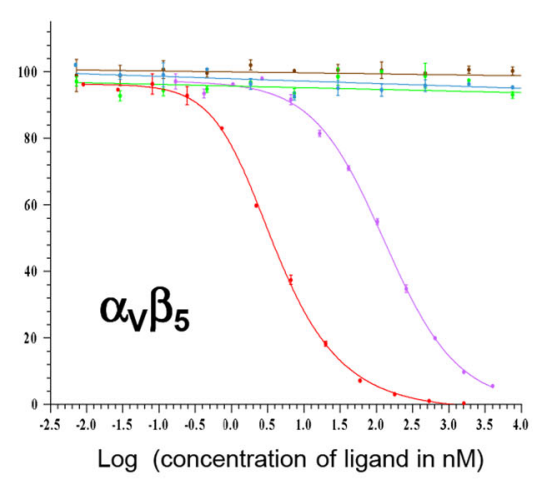

VTN: $\mathrm{IC}_{50}=0.13 \mu \mathrm{M}$

Echistatin: $\mathrm{IC}_{50}=0.004 \mu \mathrm{M}$

Fig. 1 Results of the competition study. Competition curves between ${ }^{125}$ ISIB-echistatin and ligands on the recombinant human integrins $a_{v} \beta_{6}$, $a_{5} \beta_{1}, a_{v} \beta_{1}, a_{v} \beta_{3}$, and $a_{v} \beta_{5}$. The ligands were vitronectin (VTN) fragment 381-397 aa, VTN fragment 365-381 aa, and total VTN. NOTA was used as negative control. The $I_{50}$ values of ligands able to inhibit the echistatin interaction with recombinant human integrins are indicated.

obtained with human FLSs $(n=4)$ was significantly shifted from $53 \pm 21$ to $134 \pm 29$ in the presence of $\alpha_{\mathrm{V}} \beta_{6}$ antibody $(p$-value $=0.002)$. No significant variation in MFI was observed with the secondary antibody (Fig. 2b). However, it is noteworthy that strong basal autofluorescence of human FLSs was observed compared to control U87 cells $(33 \pm 3.2$, data not shown). Supplementary information SI2 illustrates three other patients whose FLSs were analyzed by FACS.

These data confirmed the presence of the $\alpha_{V} \beta_{6}$ integrin antibody on the cellular surface of the cellular membrane in FLSs from the OA patients. To confirm the presence of the $\alpha_{\mathrm{v}} \beta_{6}$ integrin in situ, we performed IHC analysis of synovial membranes provided from healthy individuals and OA patients and used an antibody directed against the $\beta_{6}$ subunit (Fig. 2c).

\section{Increased expression of the $\beta 6$ subunit in FLSs and arthritic} synovitis under profibrotic conditions

We then wanted to evaluate whether the expression of the $\alpha_{V}$ and $\beta_{6}$ subunits could be modulated in human FLSs by (i) a profibrotic mediator (TGF- $\beta 1$ ), (ii) proinflammatory cytokines (TNF- $\alpha$, IL- $1 \beta$, and IL-6), (iii) danger-associated molecular patterns (HMGB1, S100A9, S100A12), (iv) advanced glycation end products (AGEBSA), (v) drugs (prednisolone, dexamethasone), and (vi) oxidative stress (menadione, $\mathrm{H}_{2} \mathrm{O}_{2}$ ). We observed that none of these treatments influenced the expression levels of the $\alpha_{V}$ and $\beta_{6}$ integrin subunits (Supplementary information SI3), except TGF- $\beta 1$, which significantly increased $\beta_{6}$ expression $(n=12)$ (Fig. 2d and e). Accordingly, $\beta_{6}$ expression was evaluated in synovial tissues provided from the patients with OA $(n=9)$, CPPA 

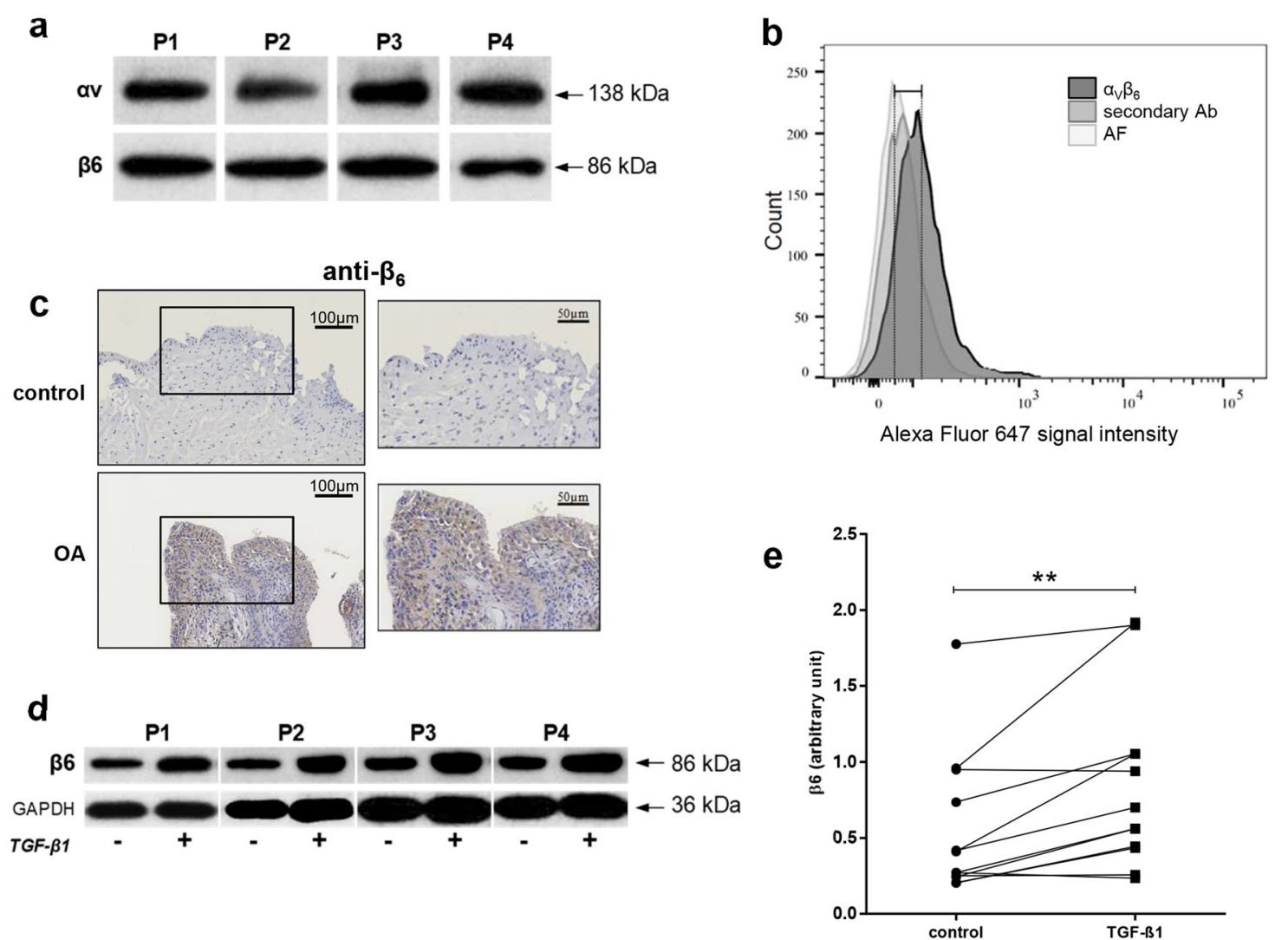

Fig. 2 In vitro and in situ expression of the $\alpha_{v}$ and $\beta_{6}$ subunits or the $\alpha_{v} \beta_{6}$ complex on FLSs. a Expression of the $a_{v}$ and $\beta_{6}$ subunits shown by western blots of human fibroblast-like synoviocytes (FLSs) from four representative patients. $\mathbf{b}$ FACS histograms of flow cytometric analysis of FLSs from a patient with OA. Profiles of cell surface expression of the $a_{v} \beta_{6}$ integrin (dark gray) and controls: secondary antibody (Ab) alone (light gray) and autofluorescence (AF; lighter gray). This is the result from a representative patient; in supplementary information SI2, histograms from three other patients are shown. $\mathbf{c}$ Immunohistochemistry of human synovial membranes. Representative images of $\beta_{6}$ in biopsies from a healthy donor (control) and an OA patient. $\mathbf{d}$ Representative images and quantification e of $\beta_{6}$ signaling after TGF- $\beta 1$ treatment. Values were normalized to that of glyceraldehyde 3-phosphate dehydrogenase (GAPDH). ${ }^{* *} p$-value $\leq 0.01$.

$(n=7)$, and RA ( $n=7)$. These biopsies were characterized by the $\alpha$-SMA expression level, a fibrotic marker, as well as by HIS based on the following features: hyperplasia and infiltration of lymphocytes, plasma cells, neutrophils and macrophages, resulting in an HIS ranging from 0 to 18 . The highest value of 18 represents the most inflamed synovitis. First, the $\beta_{6}$ subunit was detected by IHC in 23 synovial biopsies. $\beta_{6}$ staining was judged positive by the presence of brown staining in the cytoplasm (Fig. 3a). Then, with Spearman correlation analysis, a statistically significant correlation was observed between the $\beta_{6}$ percentage and $\alpha$-SMA expression $(r=0.64, p$-value $=0.001)$ and, to a lesser extent, between the $\beta_{6}$ percentage and HIS $(r=0.45, p$-value $=0.031)$, confirming the in vitro results (Fig. 3b).

\section{Human FLSs activate human latent TGF- $\beta$}

Integrin $\alpha_{\mathrm{V}} \beta_{6}$ is known to play a role in fibrosis ${ }^{13}$ and in the activation of latent TGF- $\beta 1$, a profibrotic mediator once activated $^{34}$. Based on our previous results, we wanted to confirm that (i) latent TGF- $\beta 1$ could be activated in the presence of osteoarthritic FLSs and that (ii) the $\operatorname{VTN}_{(381-397 \text { a.a.) }}$ peptide could interact with $\alpha_{\mathrm{V}} \beta_{6}$.

A quantitative TGF- $\beta$ bioassay was applied to evaluate the activation of the TGF- $\beta 1$ precursor based on its ability to induce PAI-1 expression. For this purpose, TMLCs were stably transfected with a construct containing the PAI-1 promoter fused to luciferase. In the presence of bioactive TGF- $\beta 1$, increased PAI-1 expression resulted in a dose-dependent increase in luciferase activity in the cell lysates ${ }^{29}$. Low $\mathrm{pH}$ and interaction with integrin $\alpha_{\mathrm{V}} \beta_{6}$ are two mechanisms known to activate latent TGF- $\beta 1^{35}$. Therefore, to determine whether human FLSs can enhance TGF- $\beta 1$ activation, we performed coculture with FLSs and TMLCs in the presence of latent TGF- $\beta 1$. First, we observed that FLSs $(n=14)$ did not spontaneously produce a notable amount of active TGF- $\beta 1$ in coculture, as shown in Fig. 4a. However, we observed a significant 


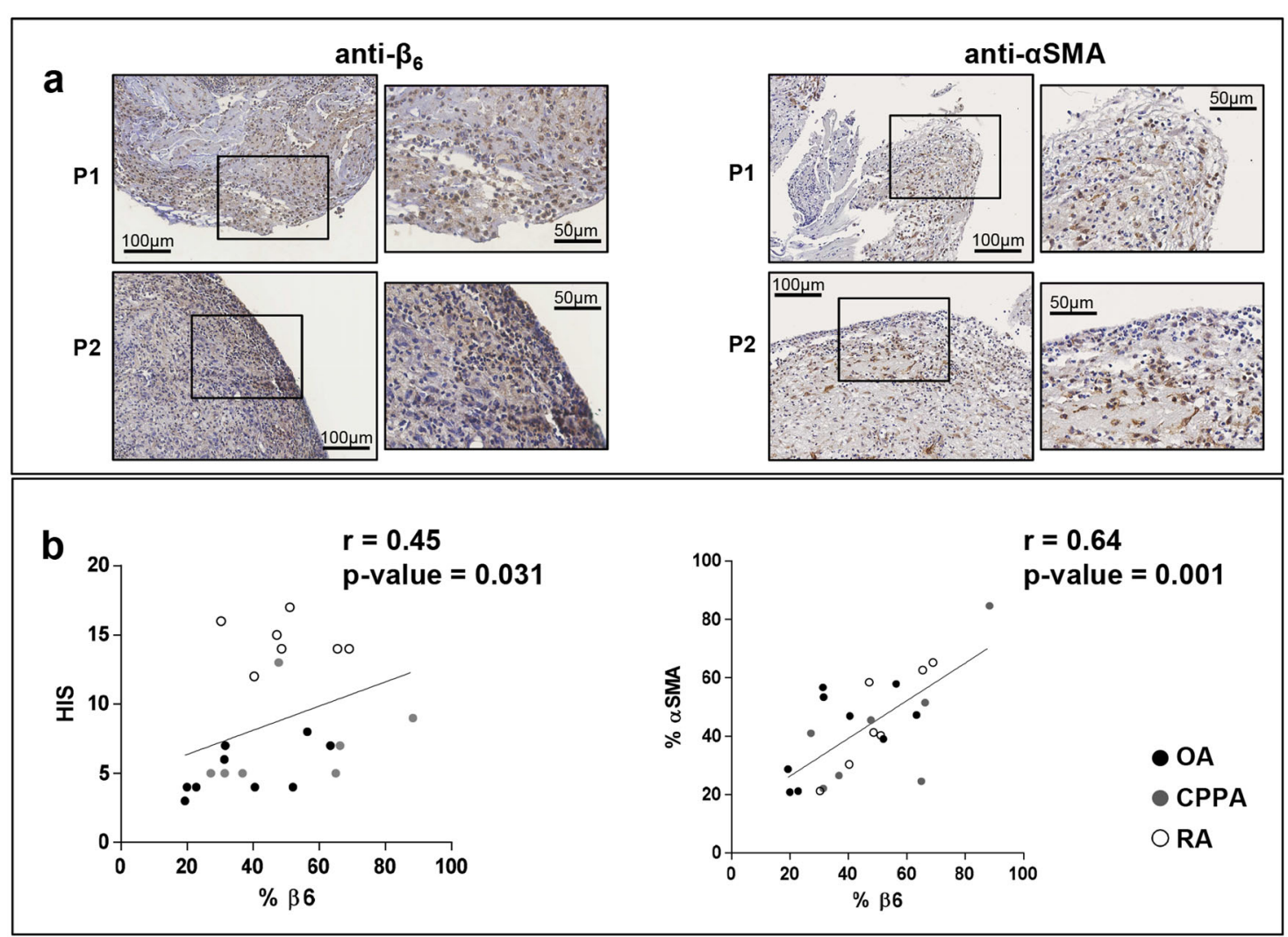

Fig. 3 Expression of $\beta_{6}$ in synovial membranes. a Immunohistochemistry on human synovial membranes. Representative images of $\beta_{6}$ and a-SMA expression in biopsies from two different OA patients (P). $\mathbf{b}$ Spearman correlation analysis was applied to examine the correlation of the $\beta_{6}$ percentage with the total histological inflammatory score (HIS) and a-SMA; $r=$ Spearman coefficient. OA Osteoarthritis, CPPA chronic pyrophosphate arthropathy, RA rheumatoid arthritis.

activation of latent TGF- $\beta 1$ when FLSs were present, similar to TGF- $\beta 1$ activation under acidic conditions (Fig. 4b). This finding strongly suggests that TGF- $\beta 1$ activation is mediated by FLSs. Further, to confirm that $\alpha_{\mathrm{V}} \beta_{6}$ integrin was involved in this activation, we performed function-blocking experiments. Anti- $\alpha_{\mathrm{V}} \beta_{6}$ antibody was added to the coculture $(n=6)$, and a significant reduction in the activation of latent TGF- $\beta 1$ was observed in a concentration-dependent manner (Fig. 4c). No significant variation was observed with the isotype control (Fig. 4d). Interestingly, when $\operatorname{VTN}_{(381-397 \text { a.a.) }}$ was added to the coculture $(n=6)$, the luciferase signal decreased, suggesting that this fragment can prevent the interaction of latent TGF- $\beta 1$ with $\alpha_{\mathrm{v}} \beta_{6}$ integrin. No significant variation was observed with hepcidin, which was used as a control peptide (Fig. 4e). All the results are presented as the mean $( \pm$ SEM) of RLA.

\section{Expression of a-SMA in FLSs}

FLSs were stimulated with $\operatorname{VTN}_{(381-397}$ a.a.) with or without TGF- $\beta 1$ to evaluate the effect on the expression of the fibrotic marker $\alpha$-SMA (Fig. 5). As expected, TGF$\beta 1$ upregulated the content of the fibrotic marker $\alpha$-SMA and the presence of $\operatorname{VTN}_{(381-397 \text { a.a.) }}$ did not change this effect. Interestingly, when FLSs were treated with $\operatorname{VTN}_{(381-397 \text { a.a. })}$ at $10 \mathrm{ng} / \mathrm{mL}$, we observed a significant increase in $\alpha$-SMA. Therefore, these preliminary results suggested a profibrotic effect for the VTN fragment. The results in Fig. 5 are expressed as the ratio of the normalized optical density $v s$. the control and are shown as the mean $( \pm$ SEM).

\section{Quantification of $\operatorname{VTN}_{(381-397 \text { a.a.) }}$}

To confirm the increased expression of $\mathrm{VTN}_{(381-397 \text { a.а.) }}$ in OA, we performed nano-LC/Chip MS-MS of serum samples from the healthy controls and the patients with OA or with different chronic inflammatory diseases: RA, AS, SLE, and SSc. We confirmed that the $\operatorname{VTN}_{(381-397 \text { а.а.) }}$ levels were increased in serum from the late OA patients compared to the healthy controls $(p$-value $=0.004)$. Furthermore, we observed a significant increase in this fragment in the patients with SLE and SSc compared to the 

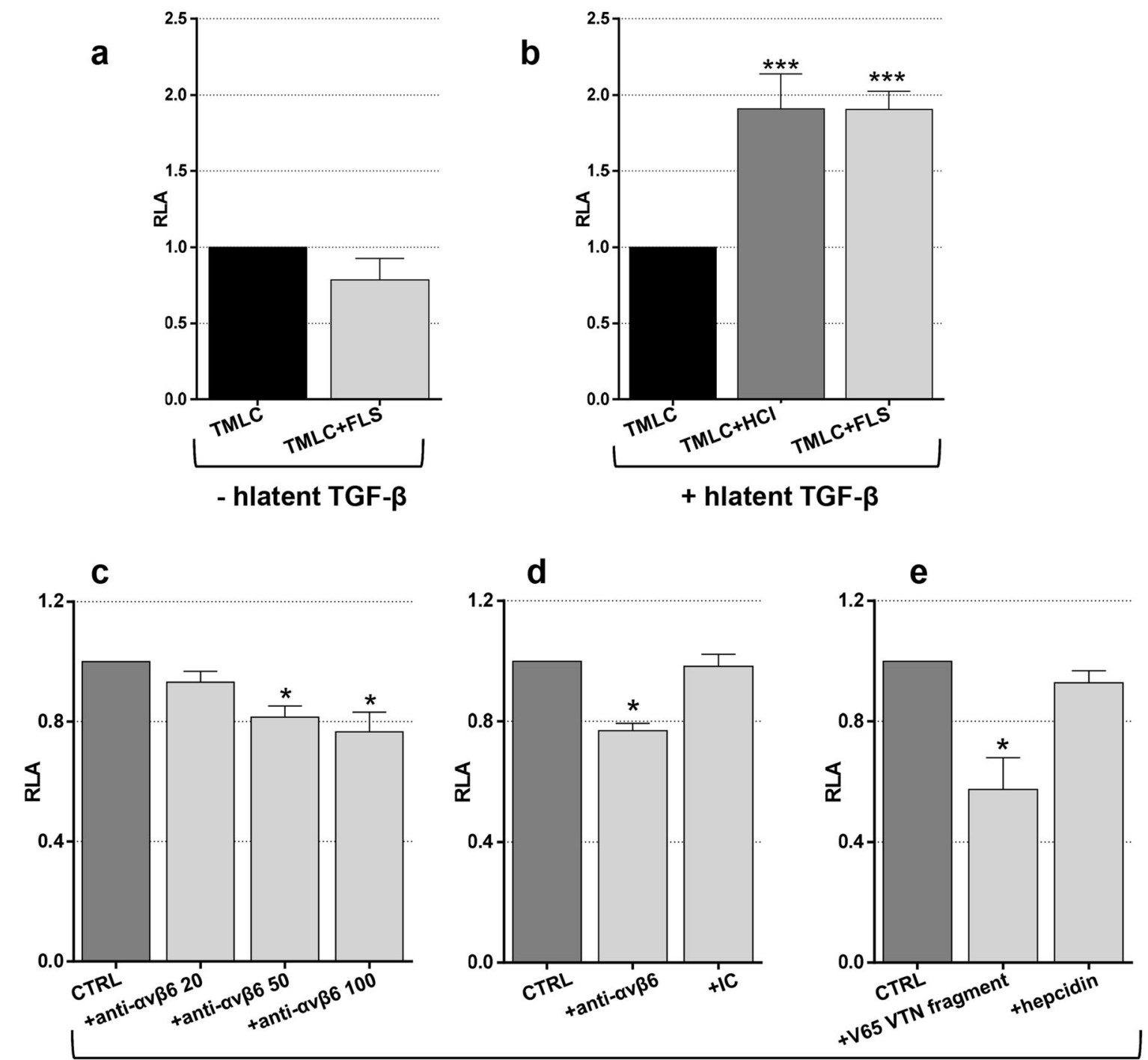

co-culture + hlatent TGF- $\beta$

Fig. 4 TGF- $\beta$ luciferase bioassay. TMLCS and human FLSs were cultured for $16 \mathrm{~h}$ and lysed to measure luciferase activity. a Spontaneous production of active TGF- $\beta$ : comparison between TMLCs and cocultures (TMLC + FLSs). $\mathbf{b}$ Activation of human latent TGF- $\beta$ by acidic activation or by the presence of human FLSs. $\mathbf{c}$ and $\mathbf{d}$ Function blocking experiments with anti- $\alpha_{v} \beta_{6}$ antibody. There was a reduction in TGF- $\beta$ activation dependent on

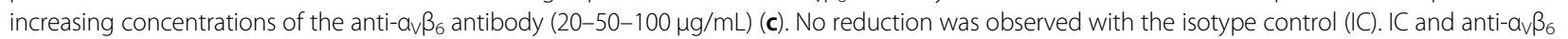
were used at $50 \mathrm{\mu g} / \mathrm{mL}$ (d). e Effect of the presence of the V65 vitronectin (VTN) fragment or peptide control (50 $\mathrm{ng} / \mathrm{mL})$. Human latent TGF- $\beta$ was used at $200 \mathrm{ng} / \mathrm{mL}$. The results are expressed as the relative luciferase activity (RLA) and are shown as the mean $( \pm S E M)$. ${ }^{*} p$-value $<0.05 ;{ }^{* * *} p$-value $\leq$ 0.0001 .

healthy subjects, with $p$-values of 0.003 and $<0.001$, respectively (Fig. 6).

\section{Discussion}

The present work relies on our previous proteomic studies, which highlighted the presence of a specific VTN fragment, $\operatorname{VTN}_{(381-397}$ a.a.), in the serum and synovial fluid of patients with $\mathrm{OA}^{15,31}$. $\operatorname{VTN}_{(381-397 \text { a.a. })}$ is a peptide composed of 17 amino acids at the C-terminal end of the V65 VTN subunit (a.a. 20-398) in the heparin-binding domain (HBD). VTN is a multifunctional ubiquitous glycoprotein produced by the liver that is secreted mostly as a serum protein and as a component of the $\mathrm{ECM}^{36}$. This molecule is also present in platelets and various human tissues ${ }^{37}$. This protein is involved in cell proliferation, differentiation, adhesion, and the immune response since it participates in fibrinolysis, coagulation, and the activation of the complement system ${ }^{37-39}$. Levels of VTN increased in pathological conditions related to acute inflammation such as RA and severe sepsis, where it 

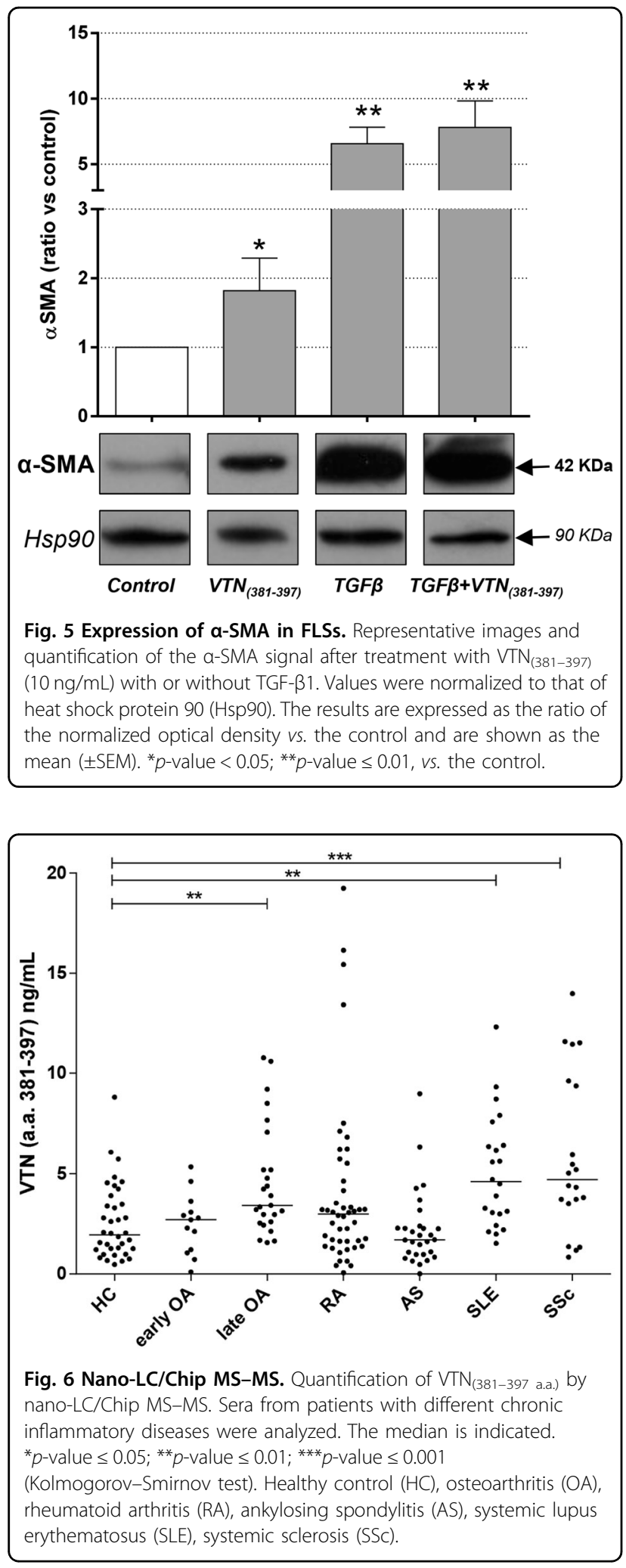

seems to contribute to organ injury ${ }^{39-41}$. Moreover, its rising levels are considered a marker of fibrotic tissues (e.g., in liver and lung $)^{42-44}$. Notably, $\operatorname{VTN}_{(381-397 \text { a.a.) }}$ is a cleaved fragment of VTN obtained by plasmin activation, reducing the affinity between VTN and PAI-1 and, consequently, fibrinolysis ${ }^{22}$.

In this study, we started to move towards a functional investigation of the role of $\operatorname{VTN}_{(381-397 \text { a.a. })}$ in OA. VTN is known to interact with integrin receptors by its RGD motif, which is positioned far upstream from $\operatorname{VTN}_{(381-397}$ a.a.) on the N-terminal end of VTN. However, Maile and colleagues also previously described a second integrin-binding site located within the HBD between amino acids 365 and $381^{32,33}$. Indeed, they demonstrated that $\operatorname{VTN}_{(365-381}$ a.a. $)$ could interact with $\alpha_{\mathrm{V}} \beta_{3}$ and that its binding was sufficient to enhance $\beta_{3}$ phosphorylation ${ }^{32}$. Considering that the fragment $\operatorname{VTN}_{(381-397 \text { a.a.) }}$ belongs to the HBD, we hypothesized that it could interact with integrins through a different site from the RGD sequence. Therefore, through a binding competition assay, we explored the interaction affinity of $\mathrm{VTN}_{(381-397 \text { a.a.) }}$ with five different integrins: $\alpha_{\mathrm{V}} \beta_{6}$, $\alpha_{V} \beta_{3}, \alpha_{V} \beta_{5}, \alpha_{V} \beta_{1}$, and $\alpha_{5} \beta_{1}$. Whole VTN showed an affinity for $\alpha_{v} \beta_{5}$ and $\alpha_{v} \beta_{6}$ had a higher affinity for integrin $\alpha_{v} \beta_{3}$, as previously described ${ }^{9,19,45-48}$. However, $\operatorname{VTN}_{(365-381 \text { a.a.) }}$ and $\mathrm{VTN}_{(381-397}$ a.a.) only showed a high affinity for integrin $\alpha_{v} \beta_{6}$ in our competition binding model.

Integrin $\alpha_{v} \beta_{6}$ is known to be a key activator of TGF- $\beta 1$ and plays a significant role in driving fibrosis (e.g., in liver, lung, and cancer $)^{9,49-51}$. Indeed, the $\alpha_{\mathrm{V}} \beta_{6}$ integrin was markedly increased in pathological fibrosis and was suggested as a potential therapeutic target. TGF- $\beta 1$ typically drives fibrotic processes ${ }^{34}$ but cannot be considered an antifibrotic target due to its ubiquitous role in tissue homeostasis. Fibrosis on synovial tissue was recently detected in $\mathrm{OA}$ and is considered one of the main causes of joint stiffness and pain ${ }^{6}$.

Thus, we have made progress by investigating the presence and regulation of this integrin in human FLSs from OA patients, which had never been observed before. Integrin $\alpha_{V} \beta_{6}$ is a heterodimer of noncovalently associated $\alpha_{V}$ and $\beta_{6}$ subunits. Using in vitro and in situ experiments, we observed the presence of the $\alpha_{\mathrm{V}} \beta_{6}$ integrin in osteoarthritic FLSs and synovial membranes. Although the presence of other integrins was previously described in $\mathrm{FLSs}^{52}$, this report is the first to show the presence of $\alpha_{\mathrm{V}} \beta_{6}$ in OA-related synovitis. By IHC, we also observed the expression of integrin $\beta_{6}$ in biopsies of synovial membranes from the patients with OA, CPPA, and RA. $\beta_{6}$ was positively correlated with the profibrotic marker $\alpha-\mathrm{SMA}^{7}$ and, to a lesser extent, with the histological inflammatory score.

In addition, many different mediators of fibrosis, inflammation, and oxidative stress were tested in vitro to study the regulation of $\alpha_{\mathrm{V}} \beta_{6}$ expression. TGF- $\beta 1$ was the only mediator able to increase $\beta_{6}$ expression. Notably, the human FLSs used for this study were derived from OA patients, and the increase would have probably been more 
striking if we had assessed FLSs from healthy controls. Anyway, treatment with TGF- $\beta 1$, a known regulator of fibrosis, induced a significant increase in the expression of the $\beta_{6}$ subunit. TGF- $\beta 1$ is required for the expression of ITGB6 ( $\beta_{6}$ integrin gene) in epithelial cells, indicating mutual positive feedback between the two molecules $^{9,53,54}$. TGF- $\beta 1$ is produced as a pro-protein that dimerizes and links to LTBP. This inactive complex made of TGF- $\beta 1$, LAP, and LTBP is referred to as a large latent complex ${ }^{35}$. Some authors found that organs have much more TGF- $\beta 1$ precursor than could be required to trigger tissue fibrosis. This indicates that the function of this growth factor in fibrosis is mainly controlled by regulation of its bioactivation rather than its secretion or synthesis ${ }^{55}$. Therefore, we used the TMLC assay to detect the presence of bioactive TGF- $\beta 1$ in cell coculture, and we observed that the presence of human FLSs could activate added latent TGF- $\beta$. The presence of an $\alpha_{v} \beta_{6}$ blocking antibody in coculture significantly reduced the bioactivation of TGF- $\beta 1$, supporting the hypothesis that $\alpha_{\mathrm{V}} \beta_{6}$ integrin is present on human osteoarthritic FLSs and that it can mediate TGF- $\beta 1$ bioavailability. However, the presence of an $\alpha_{V} \beta_{6}$ antibody in coculture did not completely abolish TGF- $\beta 1$ bioactivation because other mechanisms are probably involved in the activation of latent TGF- $\beta 1^{35}$. Indeed, $\alpha_{\mathrm{V}} \beta_{8}$ is an integrin that has been increasingly studied in fibrosis for its role as a regulator of TGF- $\beta 1$. Unlike $\alpha_{V} \beta_{6}$ and other integrins, $\alpha_{V} \beta_{8}$ appears to be only devoted to the activation of TGF- $\beta 1$ and does not interact with the cytoskeleton ${ }^{56,57}$. We detected $\alpha_{\mathrm{V}} \beta_{8}$ expression in FLSs by western blotting (we used an anti- $\beta_{8}$ monoclonal antibody, Abnova, Taipei, Taiwan; data not shown), and we also observed a significant reduction in the activation of latent TGF- $\beta 1$ when an anti- $\beta_{8}$ antibody was used in coculture of FLSs with TMLCs (monoclonal antibody, Abnova; Supplementary information SI4). Hence, the sole inhibition of the interaction of $\alpha_{V} \beta_{6}$ with TGF- $\beta 1$ cannot be sufficient to completely stop its bioactivation.

Moreover, considering that the premise of this study was the interaction of $\operatorname{VTN}_{(381-397}$ a.a.) with the $\alpha_{V} \beta_{6}$ integrin, we examined the effect of this fragment in vitro. Interestingly, when $\operatorname{VTN}_{(381-397 \text { a.a. })}$ was added to cocultures, the luciferase signal significantly decreased, suggesting that this fragment could hamper the interaction of latent TGF- $\beta 1$ with $\alpha_{V} \beta_{6}$ integrin on human FLSs in OA. In this way, we also confirmed in vitro the $\operatorname{VTN}_{(381-397 \text { a.a.) }}$ affinity for $\alpha_{v} \beta_{6}$ integrin as previously observed with the competition study.

Overall, this evidence could indicate a protective role of the fragment against fibrosis, considering the observed reduction in latent TGF- $\beta 1$ activation. However, as described above, this reduction could be bypassed by other mechanisms, such as $\alpha_{\mathrm{V}} \beta_{8}$. We recently examined the mechanisms by which $\operatorname{VTN}_{(381-397}$ a.a.) could be involved in OA. When FLSs were stimulated by $\operatorname{VTN}_{(381-397 \text { a.a.) }}$, the expression of the fibrotic marker $\alpha$ SMA increased. Interestingly, this effect was observed at a concentration close to that found in plasma for pathological conditions. This result is consistent with previous findings proposing that VTN could exacerbate lung fibrosis through the upregulation of TGF- $\beta 1$ signaling and the increase in $\alpha$-SMA transcription ${ }^{18}$. Furthermore, it has already been proposed that TGF- $\beta 1$ may induce myofibroblast differentiation by promoting differential interaction of integrins with $\mathrm{ECM}^{58}$ and that, in pulmonary fibrosis, fibroblasts express increased UPAR, which augments the binding of integrins to ECM proteins ${ }^{59}$. Thus, we could speculate that $\operatorname{VTN}_{(381-397}$ a.a.) strengthens the profibrotic TGF- $\beta 1$ pathway through $\alpha_{v} \beta_{6}$. Future studies are clearly needed to more deeply define this role and interaction.

Finally, we aimed to substantiate previous findings ${ }^{15}$ by quantifying the presence of $\operatorname{VTN}_{(381-397}$ a.a.) in serum from patients with $\mathrm{OA}$ and other inflammatory chronic diseases: RA, AS, SLE, and SSc. We applied a method of nanoliquid chromatography on chip tandem mass spectrometry that we formerly developed for the quantification of this specific fragment of $\mathrm{VTN}^{31}$. The increased expression of this peptide with respect to healthy subjects has been further confirmed in a new cohort of late OA patients but also in patients with SSc and SLE, while no rise was observed in patients with RA and AS. Hence, $\operatorname{VTN}_{(381-397 \text { a.a.) }}$ cannot be defined as a specific marker of $\mathrm{OA}$, since it is present in other rheumatic diseases, but its presence can be related to the typical ECM alteration present in fibrosis.

In conclusion, these results corroborate our previous finding that $\operatorname{VTN}_{(381-397}$ a.a.) expression levels are increased in the serum of OA patients but also in other rheumatic diseases, such as SSc and SLE. This fragment can interact with the $\alpha_{V} \beta_{6}$ integrin, a receptor whose presence was confirmed on FLSs from OA patients and is involved in the activation of latent TGF- $\beta 1$, possibly promoting fibrosis in OA. Taken together, these data warrant additional studies to unveil the fine molecular mechanisms that regulate the roles of $\operatorname{VTN}_{(381-397 \text { a.a. })}$ and integrin $\alpha_{V} \beta_{6}$. These findings will contribute to shedding light on the complexity of fibrosis in OA.

\section{Acknowledgements}

The authors would like to thank Professor Daniel B. Rifkin from New York University (Department of Cell Biology, NYU School of Medicine, New York) for the kind gift of transformed mink lung epithelial cells. The authors would also like to thank Elettra Bianchi and Philippe Delvenne (Department of Pathology, GIGA Research, CHU Liege, 4000 Liège, Belgium) for the histological

characterization of biopsies and the Biothèque Hospitalière Universitaire de Liège (ULiège and CHU de Liège) for providing FFPE sections of biopsies. This work was supported by the National Fund for Scientific Research (FNRS) —PDR: 
F5/4/5 MCF/KP and Fonds D'investissements De Recherche Scientifique (FIRS) of $\mathrm{CHU}$ de Liège.

\section{Author details}

'Laboratory of Rheumatology, GIGA-I3, University of Liège, CHU de Liège, Liège, Belgium. ${ }^{2}$ Department of Orthopedic Surgery, University Hospital SartTilman, Liege, Belgium. ${ }^{3}$ Laboratory for the Analysis of Medicines, CIRM, Department of Pharmacy, University of Liège, Liège, Belgium

\section{Conflict of interest}

The authors declare that they have no conflict of interest.

\section{Publisher's note}

Springer Nature remains neutral with regard to jurisdictional claims in published maps and institutional affiliations.

Supplementary information The online version contains supplementary material available at https://doi.org/10.1038/s12276-021-00558-2.

Received: 7 July 2020 Revised: 16 November 2020 Accepted: 16 November 2020.

Published online: 1 February 2021

\section{References}

1. Hunter, D. J. \& Bierma-Zeinstra, S. Osteoarthritis. Lancet 393, 1745-1759 (2019).

2. Vina, E. R. \& Kwoh, C. K. Epidemiology of osteoarthritis: literature update. Curr. Opin. Rheumatol. 30, 160-167 (2018).

3. Scanzello, C. R. \& Goldring, S. R. The role of synovitis in osteoarthritis pathogenesis. Bone 51, 249-257 (2012).

4. Mathiessen, A. \& Conaghan, P. G. Synovitis in osteoarthritis: current understanding with therapeutic implications. Arthritis Res. Ther. 19, 18 (2017).

5. Deroyer, C. et al. CEMIP (KIAA1199) induces a fibrosis-like process in osteoarthritic chondrocytes. Cell Death Dis. 10, 103 (2019).

6. Remst, D. F., Blaney Davidson, E. N. \& van der Kraan, P. M. Unravelling osteoarthritis-related synovial fibrosis: a step closer to solving joint stiffness. Rheumatology 54, 1954-1963 (2015).

7. Steenvoorden, M. M. et al. Transition of healthy to diseased synovial tissue in rheumatoid arthritis is associated with gain of mesenchymal/fibrotic characteristics. Arthritis Res. Ther. 8, R165 (2006).

8. Hayashi, H. \& Sakai, T. Biological significance of local TGF- $\beta$ activation in liver diseases. Front. Physiol. 3, 12 (2012).

9. Koivisto, L., Bi, J., Häkkinen, L. \& Larjava, H. Integrin avß6: Structure, function and role in health and disease. Int. J. Biochem. Cell Biol. 99, 186-196 (2018).

10. Kalli, A. C., Rog, T., Vattulainen, I., Campbell, I. D. \& Sansom, M. S. P. The integrin receptor in biologically relevant bilayers: insights from molecular dynamics simulations. J. Membr. Biol. 250, 337-351 (2017).

11. Charlier, E. et al. Toward diagnostic relevance of the aVB5, aVB3, and aVB6 integrins in OA: expression within human cartilage and spinal osteophytes. Bone Res. 8, 35 (2020).

12. Hynes, R. O. Integrins: bidirectional, allosteric signaling machines. Cell 110, 673-687 (2002).

13. Munger, J. S. et al. The integrin alpha $v$ beta 6 binds and activates latent TGF beta 1: a mechanism for regulating pulmonary inflammation and fibrosis. Cell 96, 319-328 (1999).

14. Henderson, N. C. \& Sheppard, D. Integrin-mediated regulation of TGF $\beta$ in fibrosis. Biochim. Biophys. Acta 1832, 891-896 (2013).

15. de Seny, D. et al. Discovery and biochemical characterisation of four novel biomarkers for osteoarthritis. Ann. Rheum. Dis. 70, 1144-1152 (2011).

16. Naik, M. U. \& Naik, U. P. Junctional adhesion molecule-A-induced endothelial cell migration on vitronectin is integrin alpha v beta 3 specific. J. Cell Sci. 119, 490-499 (2006).

17. Preissner, K. T. \& Reuning, U. Vitronectin in vascular context: facets of a multitalented matricellular protein. Semin. Thromb. Hemost. 37, 408-424 (2011).

18. Shen, T. L. et al. The positive role of vitronectin in radiation induced lung toxicity: the in vitro and in vivo mechanism study. J. Transl. Med. 16, 100 (2018).

19. Tian, J., Zhang, F. J. \& Lei, G. H. Role of integrins and their ligands in osteoarthritic cartilage. Rheumatol. Int. 35, 787-798 (2015).
20. Hayashida, M., Hashimoto, K., Ishikawa, T. \& Miyamoto, Y. Vitronectin deficiency attenuates hepatic fibrosis in a non-alcoholic steatohepatitis-induced mouse model. Int. J. Exp. Pathol. 100, 72-82 (2019).

21. Gundogdu, B., Yolbas, S., Yilmaz, M., Aydin, S. \& Koca, S. S. Serum osteopontin and vitronectin levels in systemic sclerosis. Adv. Clin. Exp. Med. 26, 1231-1236 (2017).

22. Chain, D., Kreizman, T., Shapira, H. \& Shaltiel, S. Plasmin cleavage of vitronectin. Identification of the site and consequent attenuation in binding plasminogen activator inhibitor-1. FEBS Lett. 285, 251-256 (1991).

23. Zhong, J. et al. Vitronectin-binding PAl-1 protects against the development of cardiac fibrosis through interaction with fibroblasts. Lab. Investig. 94, 633-644 (2014).

24. Relic, B. et al. 15-deoxy-delta12,14-prostaglandin J2 inhibits Bay 11-7085induced sustained extracellular signal-regulated kinase phosphorylation and apoptosis in human articular chondrocytes and synovial fibroblasts. J. Biol. Chem. 279, 22399-22403 (2004).

25. Sengupta, S. et al. Short hairpin RNA-mediated fibronectin knockdown delays tumor growth in a mouse glioma model. Neoplasia 12, 837-847 (2010).

26. Ning, S., Nemeth, J. A., Hanson, R. L., Forsythe, K. \& Knox, S. J. Anti-integrin monoclonal antibody CNTO 95 enhances the therapeutic efficacy of fractionated radiation therapy in vivo. Mol. Cancer Ther. 7, 1569-1578 (2008).

27. Tak, P. P. et al. Expression of adhesion molecules in early rheumatoid synovial tissue. Clin. Immunol. Immunopathol. 77, 236-242 (1995).

28. Bankhead, P. et al. QuPath: open source software for digital pathology image analysis. Sci. Rep. 7, 16878 (2017).

29. Abe, M. et al. An assay for transforming growth factor-beta using cells transfected with a plasminogen activator inhibitor-1 promoter-luciferase construct. Anal. Biochem. 216, 276-284 (1994).

30. Annes, J. P., Chen, Y., Munger, J. S. \& Rifkin, D. B. Integrin alphaVbeta6-mediated activation of latent TGF-beta requires the latent TGF-beta binding protein-1. J. Cell Biol. 165, 723-734 (2004).

31. Cobraiville, G. et al. Validation of a new method by nano-liquid chromatography on chip tandem mass spectrometry for combined quantitation of C3f and the V65 vitronectin fragment as biomarkers of diagnosis and severity of osteoarthritis. Talanta 169, 170-180 (2017).

32. Maile, L. A. et al. The heparin binding domain of VTN is the region that is required to enhance insulin-like growth factor-I signaling. Mol. Endocrinol. 20, 881-892 (2006)

33. Maile, L. A. et al. Modulation of integrin antagonist signaling by ligand binding of the heparin-binding domain of VTN to the alphaVbeta3 integrin. J. Cell. Biochem. 105, 437-446 (2008).

34. Vaamonde-Garcia, C. et al. 15-Deoxy- $\triangle$-12, 14-prostaglandin J2 acts cooperatively with prednisolone to reduce TGF- $\beta$-induced pro-fibrotic pathways in human osteoarthritis fibroblasts. Biochem. Pharmacol. 165, 66-78 (2019).

35. Robertson, I. B. \& Rifkin, D. B. Regulation of the bioavailability of TGF- $\beta$ and TGF- $\beta$-related proteins. Cold Spring Harb. Perspect. Biol. 8, a021907 (2016).

36. Montaldo, C. et al. Spike-in SILAC proteomic approach reveals the vitronectin as an early molecular signature of liver fibrosis in hepatitis $C$ infections with hepatic iron overload. Proteomics 14, 1107-1115 (2014).

37. Tsuruta, Y., Park, Y. J., Siegal, G. P., Liu, G. \& Abraham, E. Involvement of vitronectin in lipopolysaccaride-induced acute lung injury. J. Immunol. 179 7079-7086 (2007)

38. Preissner, K. T. The role of vitronectin as multifunctional regulator in the hemostatic and immune systems. Blut 59, 419-431 (1989).

39. Bae, H. B. et al. Vitronectin inhibits neutrophil apoptosis through activation of integrin-associated signaling pathways. Am. J. Respir. Cell Mol. Biol. 46, 790-796 (2012).

40. Singh, B., Janardhan, K. S. \& Kanthan, R. Expression of angiostatin, integrin alphavbeta3, and vitronectin in human lungs in sepsis. Exp. Lung Res. 31, 771-782 (2005)

41. Tomasini-Johansson, B. R., Milbrink, J. \& Pejler, G. Vitronectin expression in rheumatoid arthritic synovia-inhibition of plasmin generation by vitronectin produced in vitro. Br. J. Rheumatol. 37, 620-629 (1998).

42. Reilly, J. T. \& Nash, J. R. Vitronectin (serum spreading factor): its localisation in normal and fibrotic tissue. J. Clin. Pathol. 41, 1269-1272 (1988).

43. Koukoulis, G. K., Shen, J., Virtanen, I. \& Gould, V. E. Vitronectin in the cirrhotic liver: an immunomarker of mature fibrosis. Hum. Pathol. 32, 1356-1362 (2001).

44. Courey, A. J. et al. The vitronectin-binding function of PAl-1 exacerbates lung fibrosis in mice. Blood 118, 2313-2321 (2011).

45. Bandyopadhyay, A. \& Raghavan, S. Defining the role of integrin alphavbeta6 in cancer. Curr. Drug Targets 10, 645-652 (2009). 
46. Landen, C. N. et al. Tumor-selective response to antibody-mediated targeting of alphavbeta3 integrin in ovarian cancer. Neoplasia 10, 1259-1267 (2008).

47. Horton, M. A. The alpha v beta 3 integrin "vitronectin receptor". Int. J. Biochem. Cell Biol. 29, 721-725 (1997)

48. Hapke, S. et al. Integrin alpha(v)beta(3)/vitronectin interaction affects expression of the urokinase system in human ovarian cancer cells. J. Biol. Chem. 276 26340-26348 (2001).

49. Horan, G. S. et al. Partial inhibition of integrin alpha(v)beta6 prevents pulmonary fibrosis without exacerbating inflammation. Am. J. Respir. Crit. Care Med. 177, 56-65 (2008).

50. Popov, Y. et al. Integrin alphavbeta6 is a marker of the progression of biliary and portal liver fibrosis and a novel target for antifibrotic therapies. J. Hepatol. 48, 453-464 (2008).

51. Schnittert, J., Bansal, R., Storm, G. \& Prakash, J. Integrins in wound healing, fibrosis and tumor stroma: High potential targets for therapeutics and drug delivery. Adv. Drug Deliv. Rev. 129, 37-53 (2018).

52. Nam, E. J. et al. Up-regulated transforming growth factor beta-inducible gene h3 in rheumatoid arthritis mediates adhesion and migration of synoviocytes through alpha $\vee$ beta3 integrin: regulation by cytokines. Arthritis Rheum. 54, 2734-2744 (2006).
53. Sullivan, B. P., Kassel, K. M., Manley, S., Baker, A. K. \& Luyendyk, J. P. Regulation of transforming growth factor- $\beta 1$-dependent integrin $\beta 6$ expression by p38 mitogen-activated protein kinase in bile duct epithelial cells. J. Pharmacol. Exp. Ther. 337, 471-478 (2011).

54. Margadant, C. \& Sonnenberg, A. Integrin-TGF-beta crosstalk in fibrosis, cancer and wound healing. EMBO Rep. 11, 97-105 (2010).

55. Kim, K. K., Sheppard, D. \& Chapman, H. A. TGF- $\beta 1$ signaling and tissue fibrosis. Cold Spring Harb. Perspect. Biol. 10, a022293 (2018).

56. Nolte, M. A. \& Margadant, C. Controlling immunity and inflammation through integrin-dependent regulation of TGF- $\beta$. Trends Cell Biol. 30, 49-59 (2020).

57. McCarty, J. H. avß8 integrin adhesion and signaling pathways in development, physiology and disease. J. Cell Sci. 133, jcs239434 (2020).

58. Lygoe, K. A., Wall, I., Stephens, P. \& Lewis, M. P. Role of vitronectin and fibronectin receptors in oral mucosal and dermal myofibroblast differentiation. Biol. Cell 99, 601-614 (2007).

59. Schuliga, M., Grainge, C., Westall, G. \& Knight, D. The fibrogenic actions of the coagulant and plasminogen activation systems in pulmonary fibrosis. Int. J. Biochem. Cell Biol. 97, 108-117 (2018). 